\title{
CARNEY SYNDROME: TO BE OR NOT TO BE
}

\author{
V. Andric ${ }^{1, *}$, S. Simovic 2 , S. Catovic ${ }^{3}$, G. Davidovic ${ }^{4}$ \\ ${ }^{1}$ Health Center Raska, Raska, ${ }^{2}$ Clinic for Cardiology, Clinical Center Kragujevac, Kragujevac, ${ }^{3}$ General \\ Hospital Novi Pazar, Novi Pazar, ${ }^{4}$ University of Kragujevac, Faculty of Medical Sciences, \\ Department of Internal Medicine, Kragujevac, Serbia
}

Key words: Carney syndrome, Atrial myxoma, Adrenal adenoma.

\section{CASE PRESENTATION}

A 62-year old male was referred to cardiologist, since he was experiencing a form of a light fatigue and non-specific chest pain, unrelated to physical effort. His previous medical history showed only hypertension. Initial echocardiography revealed a normal left atria and ventricle with ejection fraction above $60 \%$. Right ventricle was dilated, while in right atria a mobile homogeneous tumor formation was observed, with dimensions $62.6 \times 35 \mathrm{~mm}$ attached to the interatrial septum (Fig. 1). Also with a protrusion into the right ventricle during diastole and moderate tricuspid regurgitation. During the preoperative assessment for a surgical extraction of the tumor, a multi-slice computed tomography of chest and abdomen was conducted. Beside right atrial myxoma in the liver, two miliary changes visible in venous phase were noted, in the $7^{\text {th }}$ and $8^{\text {th }}$ segment with dimensions of 7 and $5 \mathrm{~mm}$, respectively (Figs 2A and 2B).

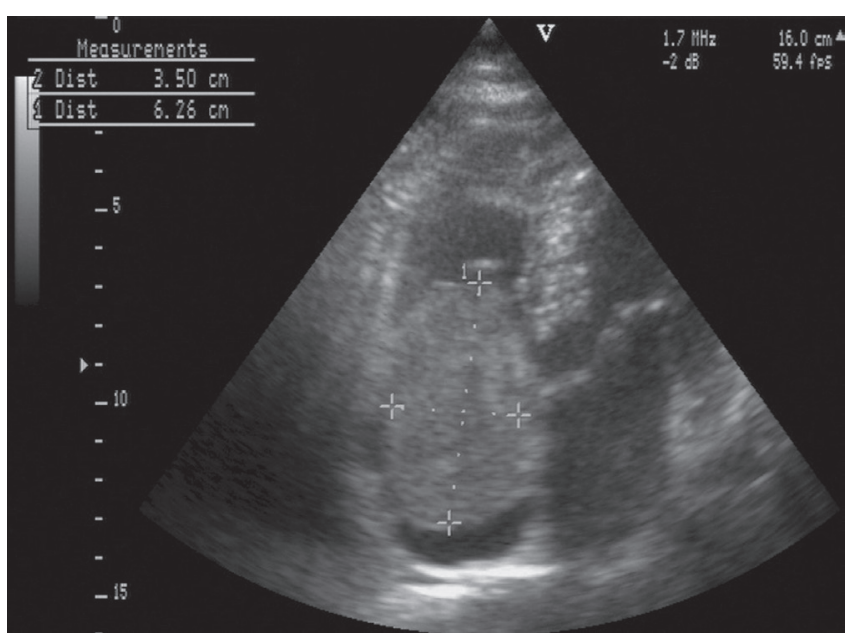

Figure 1. The myxoma in right atrium with dimensions $62.6 \times 35 \mathrm{~mm}$ and protrusion into the right ventricle.
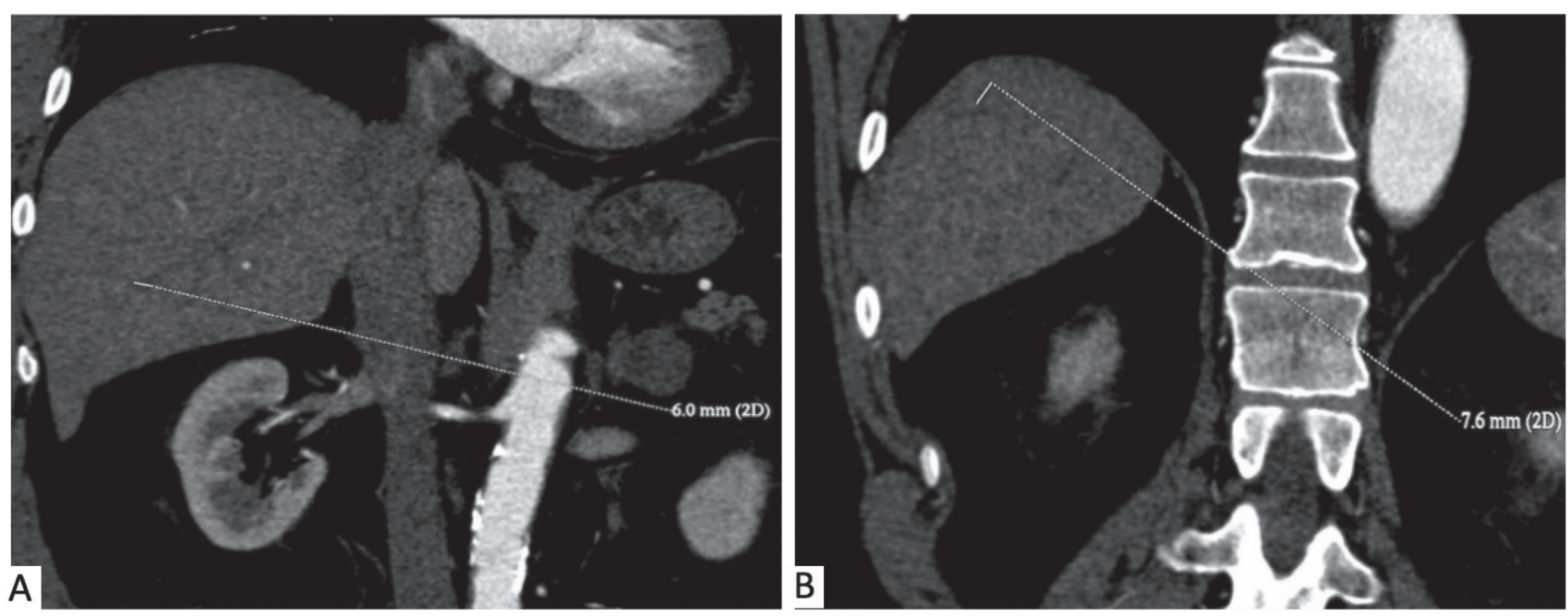

Figure 2. Two, miliary changes in the liver in $7^{\text {th }}$ and $8^{\text {th }}$ segment with dimensions of 7.6 and $6 \mathrm{~mm}$.

*Correspondence to: Stefan Simovic MD, Klinicki Centar Kragujevac, Clinic for Cardiology, Zmaj Jovina 30, Kragujevac, 34000, Serbia, E-mail: simovicst@gmail.com 


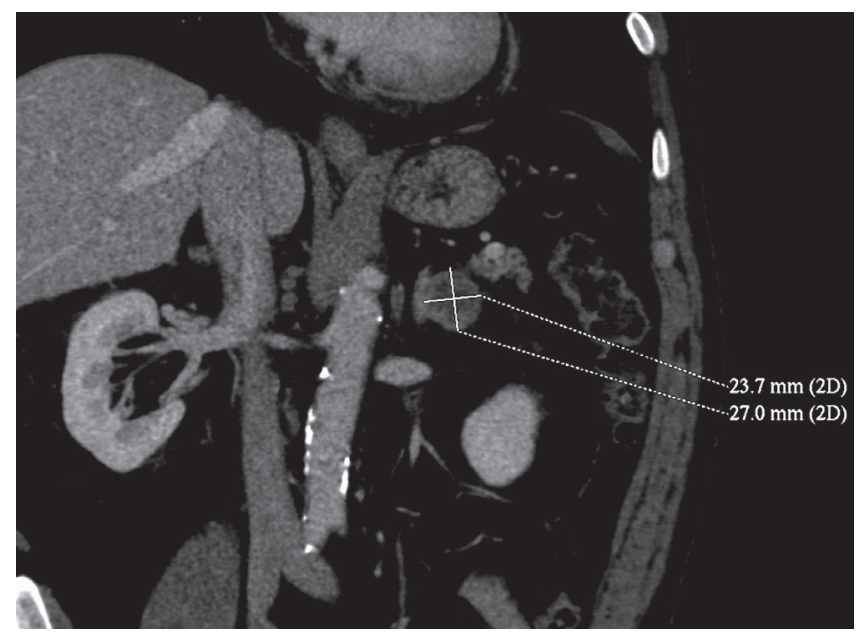

Figure 3. Enlargement of the left adrenal gland with hypovascularization and dimensions $23.7 \times 27 \mathrm{~mm}$.
Left adrenal gland was enlarged, dimensions $28 \mathrm{~mm}$, hypovascularized and without infiltration of vena cava or renal arteries (Fig. 3). After surgical treatment of the right atrial myxoma, the patient was referred to an endocrinologist. Patient's hormone analysis showed normal 24-hour urine norepinephrine, epinephrine and dopamine levels, normal values of cortisol (even after the dexamethasone suppression test) and levels of other hormones within normal range. These results lead to the conclusion that patient's subclinical functional activity of the tumor was adequately regulated, without a primary aldosteronism.

Since there was a high probability for Carney syndrome in the patient, genetic testing was conducted. The results ruled Carney's syndrome out. Therefore, observations in the form of atrial myxoma, left adrenal adenoma and hepatic changes were understood as individual. 